\title{
Are Adolescents and Youth Programs Missing The Real Targets? Analysis of Socio-Cultural Factors Influencing Use of Sexual Reproductive Health Services by Young People in Swaziland
}

\section{Bongani Robert Dlamini ${ }^{1 *}$, Phumzile Mabuza ${ }^{2}$, Margaret Thwala-Tembe ${ }^{1}$, Zandile Masangane ${ }^{2}$, Phumzile Dlamini ${ }^{1}$ and Edwin Simelane ${ }^{3}$} ${ }^{1}$ UNFPA-Swaziland

${ }^{2}$ Ministry of Health, Swaziland

${ }^{3}$ UNESCO, Swaziland

\begin{abstract}
Background: Access to reproductive health services by youth has received minimal attention given that Sexual Reproductive Health (SRH) service provision for many years has been tailored to meet the needs of the adult population. The youth have therefore been neglected partly due to cultural sensitivity that dictates what, when and how $\mathrm{SRH}$ information and services should be transmitted to them. The current study therefore sought to unveil and explore sociocultural factors influencing youth utilization of SRH services provided in health facilities.
\end{abstract}

Methods: A mixed method approach was used to gain a comprehensive view of factors influencing utilization of adolescent sexual reproductive health (ASRH) services. Data were collected quantitatively by using semi-structured questionnaires and qualitatively through individual in-depth interviews and Focus Group Discussions (FDGs) among a total of 927 youth aged 15-24 years (222 out of school youth and 705 in-school youth). The study sample also comprised of 68 gate keepers who included: teachers, religious authorities, parents/guardians, traditional authorities and health professionals.

Results: The study exposed factors underlying utilization of SRH services among Swazi youth. Such factors included the family, peers, religious and community values and norms. Youth who perceived their families, communities and peers to be liberating towards uptake of SRH services were more likely to utilize those services compared to youth who perceived the opposite.

Conclusion: The results persuade optimistic youth programs determined to increase uptake of SRH services among youth to incorporate parental and community programs instead of exclusively focusing on youth in all interventions designed to propel protective sexual behaviour among youth at all service delivery levels.

Recommendations: Parental, community, traditional and religious leadership involvement in the development and execution of youth program interventions should be prioritized.

Keywords: HIV; Adolescents; Youth; Young people

\section{Introduction}

Adolescents and youth face a multifaceted set of challenges that are inherent with the developmental stage. Adolescence is a period of mental, emotional and physical maturation which is often characterized by behavioural experimentation, identity versus role confusion, risk taking, formation of romantic relationships, sexual behaviour and drug abuse [1]. As a consequence, adolescents are vulnerable to sexually transmitted infections like HIV, teenage pregnancy, experimenting with sex, alcohol and drugs. Adolescents have inadequately developed life skills and are at risk of being coerced into sexual relationships and have limited access to health care services [2]. With regards to sexually transmitted HIV, adolescents have been labelled as the fulcrum of the HIV epidemic and the 'perfect storm' [3]. Globally, an estimated 21000 000 adolescents are living with HIV, meaning that the overabundance of health research and health information does not necessarily benefit adolescents and therefore is not translated into practice [4].

In developing countries, a majority of sexually active adolescents experience difficulty in accessing health care services, reason being that, culturally 'premarital sex is prohibited thus unmarried adolescents who are sexually active often face societal disapproval and condemnation [5]. Much focus is directed on improving access to reproductive health services for female adolescents, yet issues of reproductive health affect both male and female adolescents. Ignoring the SRH needs of male adolescents makes it even more difficult for male adolescents to access SRH services [6]. Moreover; adolescents have inadequate knowledge about contraception.
Contraceptive use among unmarried adolescents remains unknown. Although premarital sex is forbidden in Swazi culture, the fertility rate of adolescents in Swaziland is very high, reported at 87 per 1000 live births [7]. Adolescent fertility adversely affects the young woman's health, education, employment prospects as well as the infant. Adolescents sexual activity, within or outside the confines of marriage is associated with a high risk of negative reproductive health outcomes such as unintended pregnancy, sexually transmitted infections and HIV.

Generally, the policy environment for the provision of SRH services to young people is favourable in Swaziland. This is evident by the availability of various policies in support of provision of SRH services to young people. There are also a plethora of programmatic interventions regarding Sexual Reproductive Health and Rights (SRHR) in the country. However, teenage

${ }^{*}$ Corresponding author: Bongani Robert Dlamini, Program anaylst-SRH, HIV and Youth, United Nations Population Fund, Technical, Somhlolo road, Lilunga house, Second Floor, Mbabane, H100, Swaziland; Tel: +26876176844; E-mail: bonganidlamini.bd@gmail.com

Received April 06, 2017; Accepted April 13, 2017; Published April 20, 2017

Citation: Dlamini BR, Mabuza P, Thwala-Tembe M, Masangane Z, Dlamini $P$ et al. (2017) Are Adolescents and Youth Programs Missing The Real Targets? Analysis of Socio-Cultural Factors Influencing Use of Sexual Reproductive Health Services by Young People in Swaziland. J AIDS Clin Res 8: 684. doi: 10.4172/2155 6113.1000684

Copyright: (c) 2017 Dlamini BR, et al. This is an open-access article distributed under the terms of the Creative Commons Attribution License, which permits unrestricted use, distribution, and reproduction in any medium, provided the original author and source are credited. 
Citation: Dlamini BR, Mabuza P, Thwala-Tembe M, Masangane Z, Dlamini P, et al. (2017) Are Adolescents and Youth Programs Missing The Real Targets? Analysis of Socio-Cultural Factors Influencing Use of Sexual Reproductive Health Services by Young People in Swaziland. J AIDS Clin Res 8: 684. doi: 10.4172/2155-6113.1000684

Page 2 of 8

pregnancy in Swaziland remains a cause for concern. Adolescent fertility did decline slightly from $89 / 1000$ to $87 / 1000$ between 2010 and 2014, but this decrease is quite small and does not signify great success in efforts to substantially reduce early pregnancies [8]. On the hand, HIV prevalence is much higher in young women than young men across all age groups, and marked increases in prevalence become apparent throughout the $20 \mathrm{~s}$ for both sexes. This implies that in future more effort should be directed to both young men and women, targeting them by age segmentation in order to effectively respond to HIV/ AIDS. For young women, an already high rate of new infections in the 15-19 age group in noted whilst for males only increases in the early 20 s. For young men, incidence does not reach its climax until the early 30 s, though HIV incidence in young men steadily increases from adolescence onward. This data would suggest that many new infections in young women are not due to sexual intercourse with young men in their own age bracket. Rather, young women are likely being infected by older men.

Sexually active adolescents who are aware and need SRH services, such as contraceptives often do not go to the clinic for fear of health care workers' attitude and the condemnation associated with premarital sex. A majority of adolescents report attitudinal and institutional factors as main barriers to accessing SRH services [9]. Institutional barriers include location of the clinic, privacy within the facility, the age and gender of the staff complement of the clinic [10]. Health care worker's attitude has been linked to the values and beliefs about pre-marital sex [11]. Evidence has shown that culture, values and beliefs of health care workers play a critical role in deciding whether or not to provide contraception to adolescents. Health care workers, as a consequence battle between true and honest to their cultural and religious background and sensitive and accommodative of adolescents' needs [10]. This study analysed the socio-cultural factors hindering or facilitating the use of sexual and reproductive health services by young people in Swaziland.

\section{Theoretical Framework}

\section{Social ecological model (SEM)}

Due to the multiplicity of factors that influence human behavior, many recent studies have used the SEM as a conceptual framework to better understand socio-cultural factors that influence youth behavior. The SEM is a comprehensive health promotion model that is multifaceted, concerned with environmental change, behavior and policy that help individuals make healthy choices in their daily lives. It recognizes that whereas individuals are responsible for instituting and maintaining lifestyle necessary to reduce risk and improve health; individual behavior is influenced by factors at different levels. The defining feature of an SEM model is that it takes into account the physical environment and its relationship to people at individual, interpersonal, organizational and community levels. The philosophical underpinning is the concept that behavior does not occur within a vacuum, therefore the model addresses the complexities and interdependencies between socio-economic, cultural, political, environmental, organizational and biological determinants of behavior.

This approach is consistent with many theories (e.g. Social Learning Theory, Theory of Reasoned Action, and Cognitive Learning Theory) that inform adolescent pregnancy prevention evidence based interventions. The theoretical framework for most evidenced-based adolescent pregnancy prevention programs recognizes that youth are influenced by various factors- peers, family, community. The study used a Modified Social-Ecological Model. The components of the model include:

Individual: Some of these factors are age, educational level, substance use or history of abuse. Prevention strategies at this level are often designed to promote attitudes, beliefs and behaviours that ultimately promote desired behaviour; in this case utilization of sexual and reproductive health services.

Interpersonal relationship: A person's closest social circlepeers, partners and family members-influences their behaviour and contributes to their range of experience. Prevention strategies at this level may include parenting or family-focused prevention programs, and mentoring and peer programs designed to reduce conflict, foster problem solving skills and promote healthy relationships.

Community factors: The third level explores the settings, such as schools, workplaces, and neighbourhoods, in which social relationships occur and seeks to identify the characteristics of these settings that are associated with influence of behaviour in question. Prevention strategies at this level are typically designed to impact the socio-cultural and physical environment.

Societal factors: These are organizations or social institutions with rules and regulate the operations that affect how or how well, for example, SRH services are provided to an individual or group. It also includes large societal factors such as health, economic, educational and social policies that help to maintain economic or social inequalities between groups in society. Figure 1 show the conceptual framework used in the study.

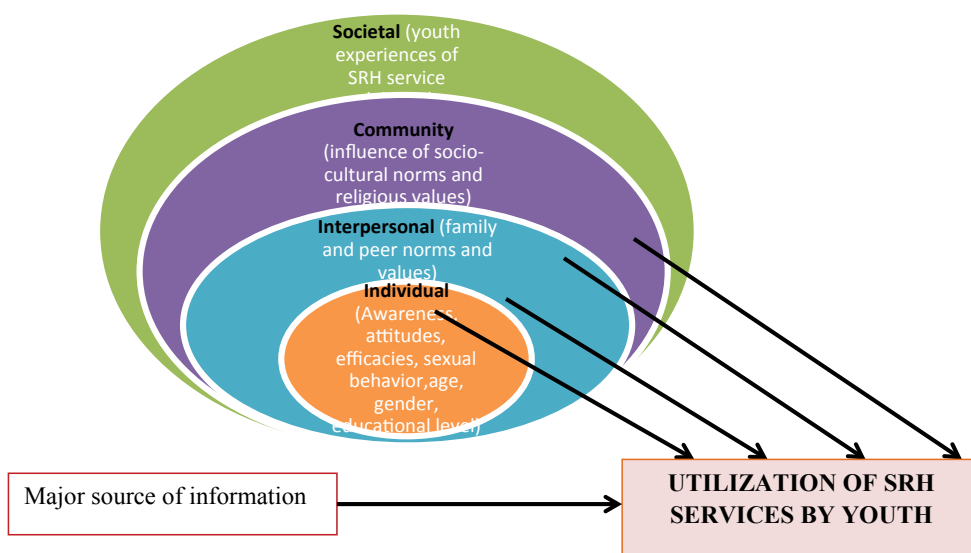

Figure 1: Modified social-ecological model (study's conceptual framework). 
Citation: Dlamini BR, Mabuza P, Thwala-Tembe M, Masangane Z, Dlamini P, et al. (2017) Are Adolescents and Youth Programs Missing The Real Targets? Analysis of Socio-Cultural Factors Influencing Use of Sexual Reproductive Health Services by Young People in Swaziland. J AIDS Clin Res 8: 684. doi: 10.4172/2155-6113.1000684

Page 3 of 8

\section{Methodology}

An exploratory descriptive mix method survey with triangulation was used in this study. The triangulation allowed both quantitative and qualitative techniques to complement each other thus ensuring adequate objective and subjective responses from youth regarding their sexual and reproductive health and rights [12]. Among gate keepers, the qualitative approach was utilized since exploration of the factors influencing utilization of SRH services by youth remain a sensitive issue thus information could only be captured through careful probing using the qualitative in-depth interviews.

\section{Data collection}

Data was collected by 21 trained data collectors (4 supervisors and 17 trained interviewers). Data was collected cross-sectionally among multi-level sampling frames (tinkhundla centres, communities, schools and health centres/clinics). Probability and non-probability sampling techniques were used in this study. Purposive sampling was used to pick 4 tinkhundla centres from each region which were equally distributed geographically. Convenience-purposive sampling was used to select study participant. With regards to the selection of inschool youth, stratified cluster random sampling was used; first for the selection of schools at random within each inkhuldla centre and then cluster sampling was used in the sense that classes were picked before randomly selecting individuals within the classes.

\section{Sampling methods}

Probability and non-probability sampling techniques were used in the study to assign research respondents into the various study samples [12]. Stratified sampling was utilised at the following strata: Inkhundla, school and participant level.

Probability sampling: The study's sample size was based on rule of thumb in structural equation modelling that asserts that the sample size should have at least 10 to 15 cases per measured indicator [13]. In the current study the structural equation modelling had 7 variables and a sample of 927 was appropriate to test the model. The size of participants in this study was also determined through the use of the raosoft sample calculator by setting a margin of error of $5 \%$ and $95 \%$ confidence interval and 50\% response distribution. The minimum recommended sample size was (764); however the study sample of 927 was way above this level. A total of 927 participants were selected from all the participating tinkhundla centres, schools and communities. The sample size was determined based on the total number of youth in Swaziland which was found to be 140000 among those aged 15-24 years [14].

\section{Study setting}

The study setting was the whole country of Swaziland, however care was taken to ensure that tinkhudla centres selected were distributed among urban and rural areas in all the four regions of the country.

\section{Data management and analysis}

Both quantitative and qualitative techniques were used to complement each other in the analysis and to enrich the discussion of study findings. Quantitative data was entered into the Statistical Package for Social Sciences (SPSS) statistics 20. The data was cleaned and analysed by the use of descriptive and inferential statistics. Inferential statistics was used to draw conclusions and make generalizations based on the information obtained from the sample. Structural Equation Modelling (LISREL 8.7) was used to predict the effect of sociocultural factors (endogenous variables: individual, interpersonal and community norms) on the utilization of SRH services among youth (exogenous variable).

\section{Ethical consideration}

The researchers had a moral obligation to strictly consider the rights of adolescents, young people and gate keepers who participated in the study. Data collectors considered it of utmost importance to build some trust between themselves and the research respondents. Permission to conduct the study was sought from the Swaziland Ethics and Scientific Committee and from the relevant authorities, particularly the Ministry of Education and Tinkhundla Administration. Informed consent was requested from the research respondents. Confidentiality was strictly adhered to. That is names of the respondents who participated in the study were not recorded. Research respondents were assured some freedom of terminating their participation at any time they would feel like doing so. A week before data collection, all the selected schools were visited for recruitment and distribution of informed consent forms among those willing to take part in the study and yet below the age of 18 years. These participants returned the forms to their class teachers the next day with signatures from parents either allowing or refusing their children's participation in the study. Pupils with consent forms ticked "No" and signed by parents were excused from participating in the study. All participants were assured of confidentiality and anonymity of their identities. Refusal to participate in the study even after informed consent was allowed.

\section{Results}

\section{Respondents characteristics}

Respondent's ages ranged from 15 years to 24 years. The mean age was 18.4 years with a standard deviation of 2.4 years. Table 1 below indicates that most out of school youth were within the age group 17-24 years with the least falling within the age group $15-16$ years $18(8.1 \%)$. An opposite trend was observed among in-school youth where the least number of respondents were within the older age groups 21-22

\begin{tabular}{|c|c|c|}
\hline Variable & Out of-school & In-school \\
\hline & $n(\%)$ & n (\%) \\
\hline \multicolumn{3}{|l|}{ Age in years } \\
\hline $15-16$ & $18(8.1)$ & $205(29.1)$ \\
\hline $17-18$ & $52(23.4)$ & $257(36.5)$ \\
\hline $19-20$ & $53(23.9)$ & $165(23.7)$ \\
\hline $21-22$ & $42(18.9)$ & $56(7.9)$ \\
\hline $23-24$ & $57(25.7)$ & $22(3.1)$ \\
\hline Total & $222(100.0)$ & $705(100.0)$ \\
\hline \multicolumn{3}{|l|}{ Region } \\
\hline Manzini & $59(26.6)$ & $169(24.0)$ \\
\hline Hhohho & $64(28.8)$ & $172(24.4)$ \\
\hline Shiselweni & $42(18.9)$ & $186(26.4)$ \\
\hline Lubombo & $57(25.7)$ & $178(25.2)$ \\
\hline Total & $222(100.0)$ & $705(100.0)$ \\
\hline \multicolumn{3}{|l|}{ Sex } \\
\hline Male & $105(47.3)$ & $343(48.7)$ \\
\hline Female & $117(52.7)$ & $362(51.3)$ \\
\hline Total & $222(100.0)$ & $705(100.0)$ \\
\hline \multicolumn{3}{|l|}{ Area of residence } \\
\hline Rural & $113(50.9)$ & $337(47.8)$ \\
\hline Urban & $109(49.10)$ & $368(52.2)$ \\
\hline Total & $222(100.0)$ & $705(100.0)$ \\
\hline
\end{tabular}

Table 1: Respondents' characteristics. 
Citation: Dlamini BR, Mabuza P, Thwala-Tembe M, Masangane Z, Dlamini P, et al. (2017) Are Adolescents and Youth Programs Missing The Real Targets? Analysis of Socio-Cultural Factors Influencing Use of Sexual Reproductive Health Services by Young People in Swaziland. J AIDS Clin Res 8: 684. doi: 10.4172/2155-6113.1000684

Page 4 of 8

and $23-24$ years at $56(7.9 \%)$ and $22(3.1 \%)$, respectively. The table also indicates that the sample is almost balanced in terms of sex, regional and residential status.

\section{Young people's sexual behaviours}

Table 2 indicates that young people continue to engage in risky behaviours. For instance almost (30\% and $20 \%$ of out of school and in school youth) reported to be taking alcohol. Moreover, 148 of 222 (66.7\%) reported sexual activity whilst 297 of 705 (42.1\%) among inschool youth reported to be non-virgins. The findings also show low level of condom use at first sex among both in-school and out-ofschool. Moreover, among sexually active youth $12.8 \%$ and $17.8 \%$ for out-of-school and in-school youth reported to have experienced forced sex. Commercial sex however seems to be much higher among out-ofschool youth, as $25.6 \%$ reported to have engaged in commercial sex whilst $10.4 \%$ had engaged in commercial sex among in-school youth.

Young people's major sources of sexual reproductive health information

Figure 2 shows that major sources of information among youth vary widely. Peers were the greatest source of SRH information (25\%), it is unfortunate however that peers often offer inaccurate and misleading information to their counterparts. Mothers on the other hand were the second most reliable source of SRH information (19.1\%), even though they seem to offer the information differentially to their male and female children. More females than males reported mothers to be their reliable and main source of information. Such findings are comforting considering the wide array of benefits manifested by mother-daughter connectedness. Teachers, siblings and fathers are also viewed as reliable

\begin{tabular}{|c|c|c|}
\hline Variable & Out of-school & In-school \\
\hline & $n(\%)$ & n (\%) \\
\hline \multicolumn{3}{|l|}{ Sexual orientation } \\
\hline Heterosexual & $211(95.0)$ & $684(97.0)$ \\
\hline Homosexual & $6(2.7)$ & $9(1.3)$ \\
\hline Bisexual & $5(2.3)$ & $12(1.7)$ \\
\hline Total & $222(100.0)$ & $705(100.0)$ \\
\hline \multicolumn{3}{|l|}{ Sexual Experience } \\
\hline Not virgin & $148(66.7)$ & $297(42.1)$ \\
\hline Virgin & $74(33.3)$ & $408(57.8)$ \\
\hline Total & $222(100.0)$ & $705(100.0)$ \\
\hline \multicolumn{3}{|l|}{ Alcohol consumption } \\
\hline Everyday & $13(5.9)$ & $7(1.0)$ \\
\hline Once a week & $35(15.8)$ & $90(12.8)$ \\
\hline Once a month & $15(6.8)$ & $27(3.8)$ \\
\hline Never & $159(71.6)$ & $581(82.4)$ \\
\hline Total & $222(100.0)$ & $705(100.0)$ \\
\hline \multicolumn{3}{|c|}{ Condom at first sex among non-virgins } \\
\hline Yes & $53(35.8)$ & $209(70.4)$ \\
\hline No & $95(64.2)$ & $88(29.6)$ \\
\hline Total & $148(100.0)$ & $297(100.0)$ \\
\hline \multicolumn{3}{|c|}{ Ever forced to have sex among non-virgins } \\
\hline Yes & $19(12.8)$ & $53(17.8)$ \\
\hline No & $129(87.1)$ & $244(82.2)$ \\
\hline Total & $148(100.0)$ & $297(100.0)$ \\
\hline \multicolumn{3}{|c|}{ Ever paid to have sex among non-virgins } \\
\hline Yes & $38(25.6)$ & $31(10.4)$ \\
\hline No & $110(74.3)$ & $266(89.6)$ \\
\hline Total & $148(100.0)$ & $297(100.0)$ \\
\hline
\end{tabular}

Table 2: Respondents sexual behaviours.

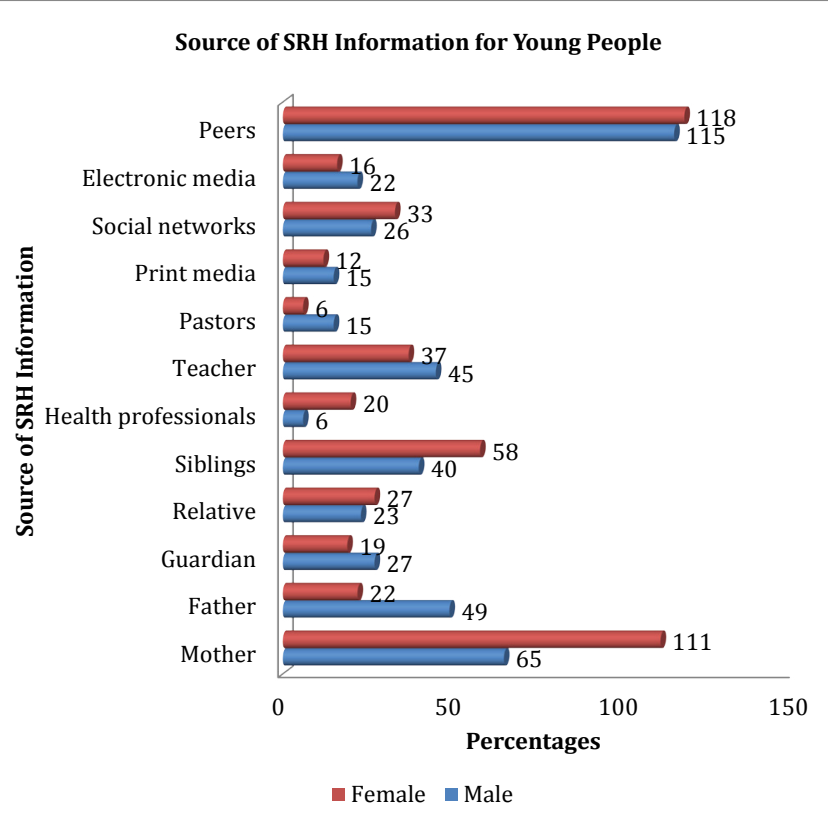

Figure 2: Sources of SRH information for young people.

\section{Use of SRH by Young People}

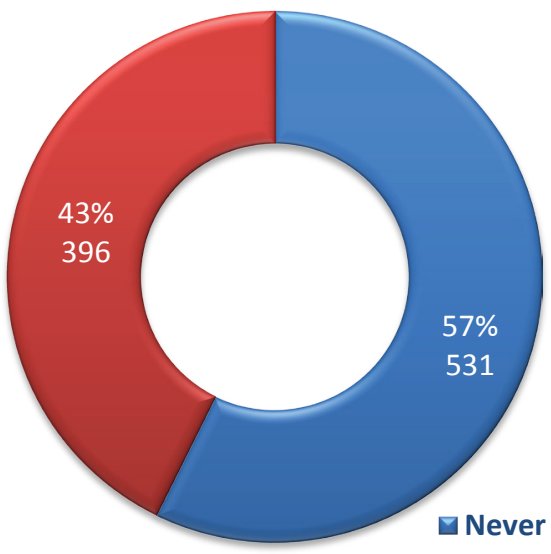

$\square$ Accessed

Figure 3: Utilization of SRH services by young people.

sources of SRH information by a substantial number of young people ( $30 \%$ collectively).

\section{Use of SRH services by young people}

Access to SRH services was defined as demonstration of health seeking behaviour coupled by access or utilization of any of the fourteen types of SRH services that encompass a comprehensive package of SRH services. The graph below shows that less than half (43\%) of 927 youth reported to have ever accessed or utilized SRH services. It is worth noting that this fraction is less than the percentage of sexually active individuals in the study sample, such findings confirm that indeed SRH services are underutilized by young people in Swaziland (Figure 3).

\section{Association between source of information and access to SRH services by young people}

Table 3 show respondents' major source of information cross tabulated by whether they have ever accessed SRH services or not. It 
Citation: Dlamini BR, Mabuza P, Thwala-Tembe M, Masangane Z, Dlamini P, et al. (2017) Are Adolescents and Youth Programs Missing The Real Targets? Analysis of Socio-Cultural Factors Influencing Use of Sexual Reproductive Health Services by Young People in Swaziland. J AIDS Clin Res 8: 684. doi: 10.4172/2155-6113.1000684

Page 5 of 8

\begin{tabular}{|l|c|c|}
\hline \multirow{2}{*}{ Major Source of Information } & \multicolumn{2}{|c|}{ Accessed SRH services } \\
\cline { 2 - 3 } & Never accessed & Accessed \\
\hline Mother & $137(25.8 \%)$ & $39(9.8 \%)$ \\
\hline Father & $40(7.5 \%)$ & $31(7.8 \%)$ \\
\hline Guardian & $25(4.7 \%)$ & $21(5.3 \%)$ \\
\hline Relative & $28(5.3 \%)$ & $22(5.6 \%)$ \\
\hline Siblings & $48(9.0 \%)$ & $50(12.6 \%)$ \\
\hline Health professionals & $10(2.0 \%)$ & $16(4.0 \%)$ \\
\hline Teacher & $59(11.1 \%)$ & $23(5.8 \%)$ \\
\hline Pastors & $12(2.3 \%)$ & $9(2.3 \%)$ \\
\hline Print media & $16(3.0 \%)$ & $11(2.8 \%)$ \\
\hline Social networks & $32(6.0 \%)$ & $27(6.8 \%)$ \\
\hline Electronic media & $22(4.1 \%)$ & $16(4.0 \%)$ \\
\hline Peers & $110(20.7 \%)$ & $123(31.1 \%)$ \\
\hline Total & $\mathbf{5 3 1 ( 1 0 0 . 0 \% )}$ & $\mathbf{3 9 6}(\mathbf{1 0 0 . 0} \%)$ \\
\hline
\end{tabular}

Table 3: Association between source of SRH information and use of SRH services among young people.

\begin{tabular}{|l|c|c|}
\hline \multirow{2}{*}{ Major Source of Information } & \multicolumn{2}{|c|}{ Sexual intercourse experience } \\
\cline { 2 - 3 } & Yes & No \\
\hline Mother & $40(9.0 \%)$ & $136(28.2 \%)$ \\
\hline Gather & $28(6.3 \%)$ & $43(8.2 \%)$ \\
\hline Relative & $14(3.1)$ & $32(6.6 \%)$ \\
\hline Siblings & $26(5.8 \%)$ & $24(5.0 \%)$ \\
\hline Health professionals & $61(13.7 \%)$ & $37(7.7 \%)$ \\
\hline Teacher & $13(2.9 \%)$ & $13(2.7 \%)$ \\
\hline Pastors & $26(5.8 \%)$ & $56(11.6 \%)$ \\
\hline Print media & $5(1.1 \%)$ & $16(3.3 \%)$ \\
\hline Social networks & $17(3.8 \%)$ & $10(2.1 \%)$ \\
\hline Electronic media & $30(6.7 \%)$ & $29(6.0 \%)$ \\
\hline Peers & $25(5.6 \%)$ & $13(2.7 \%)$ \\
\hline Total & $160(36.0 \%)$ & $73(15.1 \%)$ \\
\hline
\end{tabular}

Table 4: Association between source of information and sexual intercourse experience among respondents.

was interesting to note that among young people who relied on mothers for SRH information only (9.8\% of 396) reported to have accessed such services. On the other hand; youth who depended on peers for SRH information reported to have accessed SRH services the most $(31.1 \%$ of 396) followed by those who relied on siblings for such information (12.6\% of 396).

\section{Association between source of SRH information and sexual intercourse among respondents}

Table 4 shows association between major source of SRH information and sexual activity among young people. About $30 \%$ of the 482 (virgin youths) were youth who depended on their mothers for SRH of information yet $15 \%$ of 482 (virgin youths) considered peers as their major source of SRH information. It is evident that youth who relied on peers and siblings for SRH information are less likely to be virgins as opposed to those who relied on their mothers for such information.

\section{Providers of sexual reproductive health services for young people}

It was quite alarming to discover that even though almost half of the respondents had accessed different kinds of SRH services, most of them accessed them from pharmacies 120 (30.3\%), followed by hospitals and shops at $76(19.2 \%)$ and $72(18.2 \%)$, respectively. The least preferred SRH service providers were health centres and clinics. Furthermore,

the findings show that most females as opposed to males were likely to access SRH services from hospitals 45 (11.4\%) females vs. $31(7.8 \%)$ males, clinics 20 (5.1\%) females' vs. $9(2.3 \%)$ males and health centres 25 (6.3\%) females vs. 18 (4.5\%) males. Most males accessed such services from shops 44 (11.1\%) males' vs. 28 (7.1\%) females (Figure 4).

\section{Types of SRH services utilized by respondents from their SRH service providers}

Figure 5 show that most respondents, about a quarter (25\%) accessed condoms from shops and pharmacies. Findings also show that pharmacies are also mostly used by youth to access emergency contraception tablets however, youth mostly rely on hospitals for management of STI's and on youth centers for SRH information, sports and recreation services.

\section{Socio-cultural factors determining uptake of SRH services among young people}

When youth were asked which sociocultural factors are more influential towards their uptake of SRH services; they pointed out family values to be the most powerful followed by peer influence then teachers and health workers especially among females, as shown in Figure 6 below.

The Structural Equation Modelling (LISREL 8, 7) was used to predict the effect or weight of socio-cultural factors influencing access and use of SRH services by young people. Interpersonal norms were the strongest predictors of the uptake of SRH services among youth in Swaziland: effect coefficient $0.43, \mathrm{p}<0.01$ of which the most influential among these were

\section{SRH Service Providers for Young people Female Male}

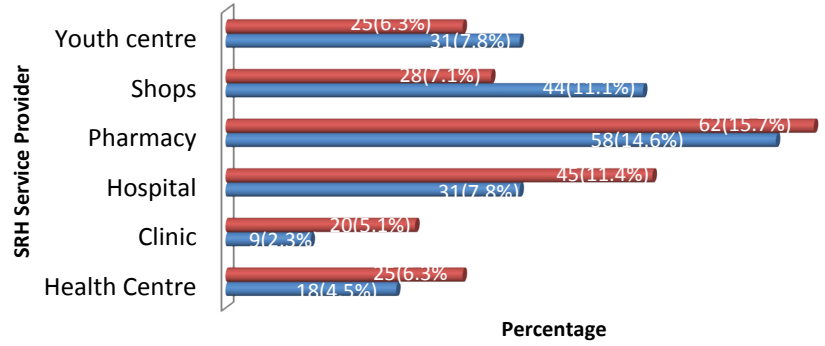

Figure 4: SRH Service providers for young people.

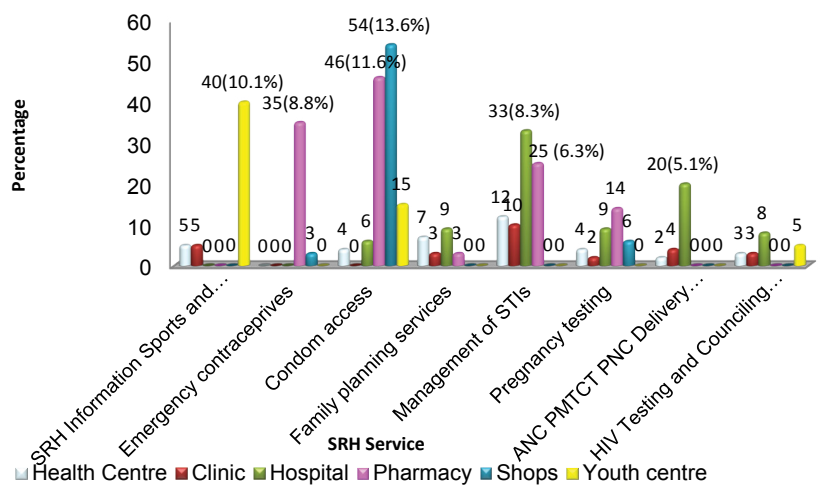

Figure 5: SRH services accessed by respondents from SRH service providers. 
Citation: Dlamini BR, Mabuza P, Thwala-Tembe M, Masangane Z, Dlamini P, et al. (2017) Are Adolescents and Youth Programs Missing The Real Targets? Analysis of Socio-Cultural Factors Influencing Use of Sexual Reproductive Health Services by Young People in Swaziland. J AIDS Clin Res 8: 684. doi: 10.4172/2155-6113.1000684

Page 6 of 8

the family norms $(\mathrm{r}=0.90)$ followed by peer norms $(\mathrm{r}=0.71)$. The second strongest predictors of the utilization of SRH services among youth were community norms and values: effect coefficient $0.19, \mathrm{p}<0.05$ amongst which communal norms $(\mathrm{r}=0.80)$ were more persuasive than religious norms $(\mathrm{r}=0.44)$. Individual norms were poor predictors of SRH service utilization among youth: effect coefficient $0.01, \mathrm{p}>0.05$; condom attitudes were more forceful than the efficacy of using condoms ( $r=61$ and $r=24$, respectively) within the individual level factors (Figure 7)

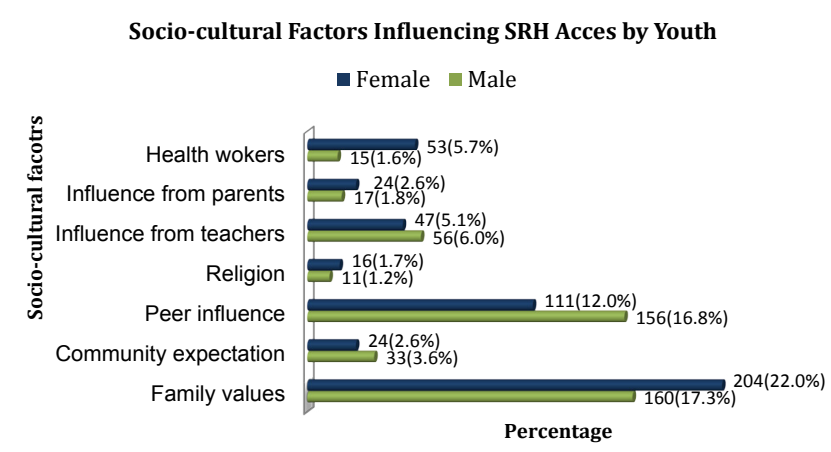

Figure 6: Socio-cultural factors influencing access to SRH services by respondents.

\section{Discussion}

This study attempted to empirically fill the knowledge gap in literature regarding determinants of SRH service uptake among the youth in Swaziland. A clear understanding of these determinants is crucial in developing and implementing appropriate interventions that will promote and sustain effective uptake of SRH services among the youth. Findings confirmed the continuance of risky sexual practices; premarital sex and low condom use among Swazi youth. Such findings are comparable to previous findings from nationwide behavioural surveys in Swaziland, pointing out that a substantial number of the inschool youth are sexually active and yet barely use condoms, particularly at first sex. This poses a serious concern, considering that these young people are more vulnerable to STI's and HIV due to possible abrasion and tearing of their immature reproductive tracts, particularly on their first sexual encounters.

The study observed that the effect of individual factors such as personal characteristics, attitudes towards condom use, condom selfefficacy and SRHR awareness on uptake of SRH services by youth were poor predictors of the utilization of SRH services among youth. Previous literature has established that individual behaviour is mostly influenced by societal norms in most African societies. Moreover, according to adolescents and youth in Swaziland do not have adequate information and accessibility to services which will enable them to

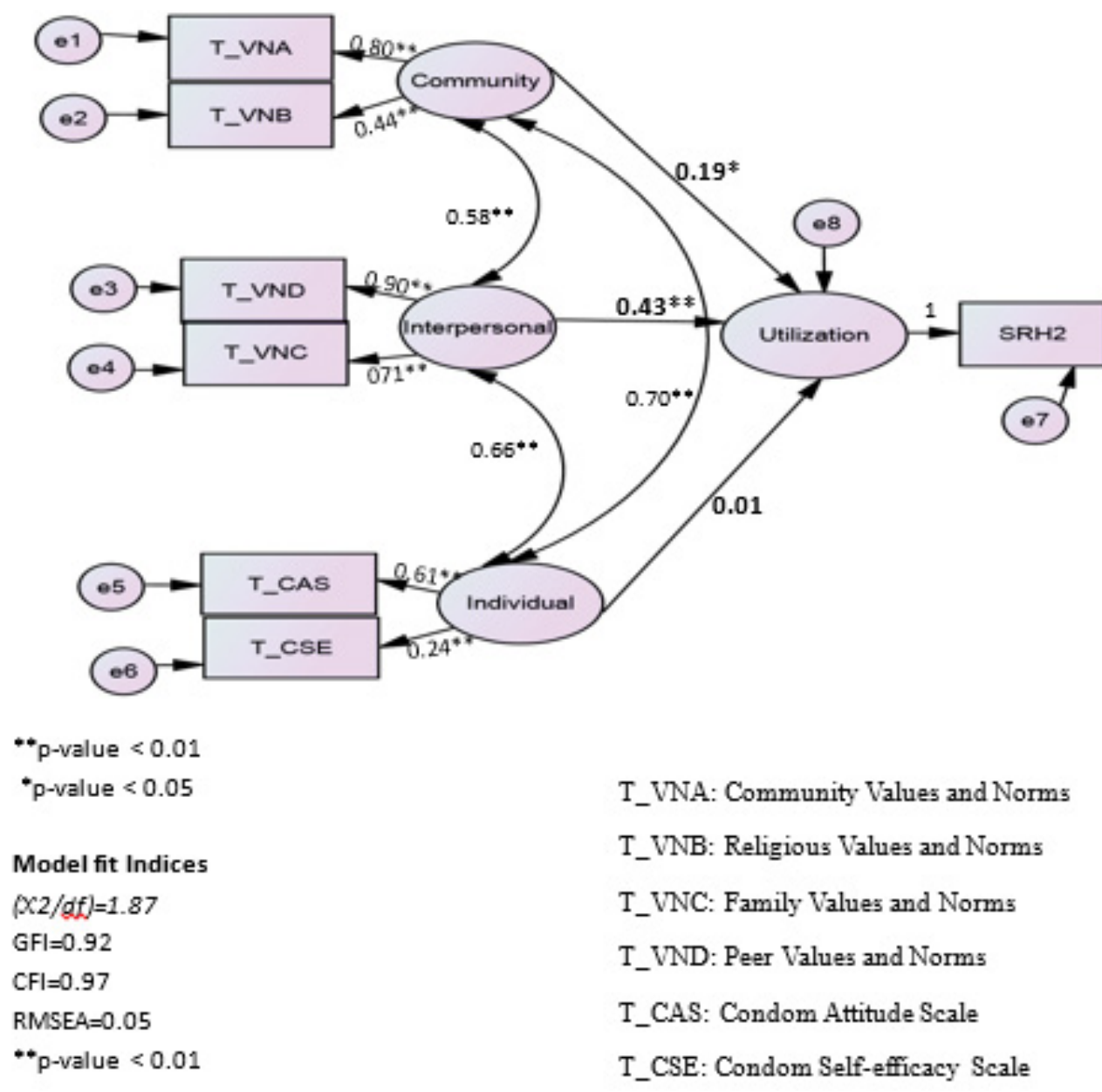

Figure 7: Structural equation modelling of socio-cultural factors influencing access of SRH services by young people. 
Citation: Dlamini BR, Mabuza P, Thwala-Tembe M, Masangane Z, Dlamini P, et al. (2017) Are Adolescents and Youth Programs Missing The Real Targets? Analysis of Socio-Cultural Factors Influencing Use of Sexual Reproductive Health Services by Young People in Swaziland. J AIDS Clin Res 8: 684. doi: 10.4172/2155-6113.1000684

Page 7 of 8

make informed decisions on their sexuality and reproductive health, particularly HIV [15]. Young people engage in sexual activity at early ages, and with limited knowledge of sexual and reproductive health and rights, lack skills to negotiate safer sex, access appropriate health commodities and exhibit poor health-seeking behaviour.

The influence of interpersonal factors were also studied in relation to the utilization of ASRH services was also investigated and what transpired from findings was that both family and peer norms significantly increased the SRH service utilization likelihood among youth. The positive impact of parents on adolescent sexual behaviour is continuously being brought to the fore by numerous studies [16]. These findings highlight the need for parental programs designed to empower parents, especially fathers on how to effectively monitor and communicate to their children on sensitive issues such as condom use. A recent systematic review of behavioural intervention studies designed to improve parent's ability to communicate with their children found that compared to control groups, parents who participated in interventions experienced significant improvements in the frequency, quality, intentions, comfort and efficacy for communicating to their adolescent children about sexual and reproductive health issues [3].

Community norms were found to significantly predict the utilization of SRH services among youth in Swaziland; however religious norms were not significant predictors of such behaviour. This may be due to the close relationship between family and community norms. Youth who perceived their parents as supportive towards utilization of SRH services were likely to perceive the community as less judgmental towards uptake of such services. Religion on the other hand seemed not to be accommodative of SRH service utilization despite the rate of teenage pregnancy in churches and communities at large. These finding highlights the need to strengthen community based education programs in-order ensure that harmful socio-cultural factors do not hinder efforts designed to promote SRH service uptake among youth.

\section{Conclusion and Recommendations}

Given that, to date, there is limited empirical data supporting the applicability of theory based models in Swaziland, this study provides proof of the applicability of the Socio-Ecological Model (SEM) among in-school youth and out of school youth within the age group 15 to 24 years. The study also advances theoretical research by presenting a different approach of modeling the Socio-Ecological Model. The study also provides support of the applicability of the SEM in predicting factors determining utilization of SRH services among youth in a Swazi context. Furthermore the findings revealed that family; peer and community norms play a vital role in promoting utilization of SRH services among youth.

Major findings were yielded by the study. First of all, the efficacy of the Socio-Ecological Model among youth was supported by findings, which shows that the model has utility for guiding interventions aimed at promoting utilization of ASRH services. Secondly factors underlying utilization of SRH services among Swazi youth were unveiled in this study which means that, the fundamental goal of promoting utilization of SRH services among youth lies in positively shaping family values, Peer influence, community influence, attitudes towards condom use and promoting SRHR awareness to favour uptake of SRH services among youth aged 15 to 24 years. Therefore, this could be a guide in designing effective, culturally sensitive youth programs which are specific to the Swazi content. Current results persuade optimistic youth programs determined to conquer HIV among the youth to integrate parental, cultural and youth programs and not to exclusively focus on any of them. The SEM model may ultimately contribute to the establishment of policies to guide sexual behaviour intervention strategies among Swazi youth.

Key recommendations for effective adolescents and youth Sexual and Reproductive Health and Rights programming are below.

1. Parental involvement: this should involve the development of a standardized training manual for parental education on SRH issues. Parental involvement in the planning and execution of youth program interventions and formation of parental support programs is paramount if youth programs are to yield results.

2. Community involvement: Community mobile clinics are a necessity in all communities to offer SRH services and coverage of youth programs should be extended. Sustainability should be ensured through availability and consistency. Formation of youth SRH clubs in all communities which will go beyond education but invent innovative activities that will groom young people holistically.

3. Involvement of religious leaders and traditional authorities: SRH education in churches based on agreed upon curriculum with religious leaders as well as traditional authorities is important, as well as the involvement of traditional authorities in all community based adolescent and youth SRH interventions should be done.

\section{Limitations of the study}

Regardless of the afore mentioned contributions, the study portrays the following limitations; the causal direction between sociocultural factors and the actual behaviour as lived by participants required more stronger methodologies such as longitudinal study designs therefore it could not be examined in this cross-sectional study. The sensate nature of the topic may have led to the underreporting of youth sexual behaviour, however given that, the questionnaire was anonymous, completed independently in an interview, without prior consulting or discussing questions respondents limited the likelihood to record inaccurate information. Current findings may not be applicable to other groups of young people such as the college and university students however; the high response rate and sampling approach (stratified random sampling) enhance generalizability of findings to a wider population range, given that Swaziland is a homogenous country.

\section{Acknowledgement}

The authors are grateful to all the respondents who voluntarily participated in the study.

\section{References}

1. Brown L, Macintyre K, Trujillo L (2014) Interventions to reduce HIV/AIDS stigma: What have we learned? AIDS Educ Prev 15: 46-69.

2. Kim YM, Kols A, Nyakauru R, Marangwanda C, Chibatamoto P (2014) Promoting sexual responsibility among young people in Zimbabwe. Int Fam Plan Perspect 27: 11-19.

3. Abrahams M (2015) Social Identity Theory In Burke PJ (ed.) Contemporary social psychological theories. Stanford University Press Amazon, New York 2015.

4. Muula A, Thomas J, Pettifor A, Strauss R, Suchindran C, et al. (2012) Religion is not associated with HIV infection among women in Malawi. Int J Disabil Hum Dev 11: 121-131.

5. Jejeebhoy S, Bott S (2015) Non-consensual sexual experiences of young people: A review of the evidence from developing countries. Annual Meeting of the Population Association of America, Minneapolis, Minnesota.

6. Chege F (2007) Researching gender: Explorations into sexuality and HIV 
Citation: Dlamini BR, Mabuza P, Thwala-Tembe M, Masangane Z, Dlamini P, et al. (2017) Are Adolescents and Youth Programs Missing The Real Targets? Analysis of Socio-Cultural Factors Influencing Use of Sexual Reproductive Health Services by Young People in Swaziland. J AIDS Clin Res 8: 684. doi: 10.4172/2155-6113.1000684

Page 8 of 8

AIDS in African contexts. Research consortium on educational outcomes and poverty, University of Cambridge, London.

7. Central Statstics Office (2014) Multiple indicator cluster survey. Government of the Kingdom of Swaziland, Mbabane.

8. Central Statistics Office (2014) Multiple indicator cluster survey key findings. Government of the Kingdom of Swaziland, Mbabane.

9. Buzi RS, Smith PB (2014) Access to sexual and reproductive health care services: Young men's perspectives. J Sex Marital Ther 40: 149-157.

10. Godia PM, Olenja JM, Hofman JJ, Broek N (2014) Young people's perception of sexual and reproductive health services in Kenya. BMC Health Serv Res 14: 172.

11. Mngadi PT, Faxelid Zwane IT, Höjer B, Ransjo-Arvidson B (2008) Health providers' perceptions of adolescent sexual and reproductive health care in Swaziland. Int Nurs Rev 55: 148-155

12. Burns and Grove (2009) The practice of Nursing Research; appraisal, synthesis and generation of evidence.

13. Stevens RD, Edwards ND (1996) An approach to the evaluation of assistive technology. In Proceedings of Assets. ACM 64-71.

14. Central Statistics Office (2007) Demographic and health survey. Government of the Kingdom of Swaziland, Mbabane.

15. Central Statistical Office (2016) Swaziland Multiple Indicator Cluster Survey 2014. Central Statistical Office and UNICEF, Mbabane.

16. Adimora AA, Schoenbach VJ (2010) Social context, sexual networks and racia disparities in rates of sexually transmitted infections. J Infect Dis 191: S115-S122. 